\title{
PENGEMBANGAN SOAL TIPE PISA UNTUK MENGUKUR KEMAMPUAN KOMUNIKASI MATEMATIS SISWA TINGKAT SEKOLAH MENENGAH PERTAMA DI KOTA JAMBI
}

\author{
Aisyah $^{1}$, Sri Dewi ${ }^{2}$ \\ Program Studi Pendidikan Matematika, FKIP, Universitas Batanghari ${ }^{1,2}$ \\ Jl. Slamet Riyadi No.1 Broni Jambi \\ email: aisyah.aisyah55@yahoo.co.id
}

\begin{abstract}
ABSTRAK
Soal-soal tipe PISA merupakan salah satu tipe soal yang dapat digunakan untuk mengembangkan kemampuan berpikir tingkat tinggi (high order thinking) siswa, salah satunya kemampuan komunikasi matematis. Karena itu dikembangkan soal-soal tipe PISA untuk mengukur kemampuan komunikasi matematis siswa. Rumusan masalahnya yaitu; 1) Bagaimanakah mengembangkan soal-soal tipe PISA yang valid dan praktis untuk mengetahui kemampuan komunikasi matematis siswa tingkat SMP? 2) Bagaimanakah efek potensial uji coba soal-soal tipe PISA yang dihasilkan terhadap kemampuan komunikasi matematis siswa SMP N 17 Kota Jambi? Sedangkan tujuannya adalah 1) Menghasilkan soal tipe PISA yang valid dan praktis untuk mengetahui kemampuan komunikasi matematis siswa tingkat SMP, 2) Mengetahui efek potensial penerapan soal-soal tipe PISA yang dihasilkan terhadap kemampuan komunikasi matematis siswa SMPN 17 Kota Jambi. Metode penelitiannya development research dengan subjek penelitian siswa kelas IX SMP N 17 Kota Jambi. Teknik pengumpulan data yang digunakan; 1) walk trough, 2) dokumentasi, 3) tes dan wawancara. Hasil penelitian ini adalah soal-soal matematika tipe PISA untuk mengetahui kemampuan komunikasi matematis siswa sebanyak 10 butir berbentuk uraian (open construct response) yang valid dan praktis. Soal-soal ini mempunyai efek yang diketahui dari analisis jawaban siswa dan wawancara ketika pelaksanaan uji coba soal dimana siswa dapat mengeksplor kemampuan komunikasi matematisnya.
\end{abstract}

Kata kunci:

soal tipe PISA, komunikasi matematis.

\begin{abstract}
PISA type questions are one type of questions that can be used to develop students' high order thinking skills, one of which is mathematical communication skills. Because of that, developed PISA type questions to measure students' mathematical communication skills. The formulation of the problem namely; 1) How to develop valid and practical PISA type questions to find out the mathematical communication skills of junior high school students? 2) What is the potential effect of the PISA test problems generated on the mathematical communication skills of students of SMP N 17 Jambi City? While the objectives are 1) Generating valid and practical PISA type questions to find out the mathematical communication skills of junior high school students, 2) Knowing the potential effects of applying PISA type questions generated on the mathematical communication skills of SMPN 17 Jambi City students. The research method is development research with research subjects of class IX students of SMP N 17 Jambi City. Data collection techniques used; 1) walk through, 2) documentation, 3) tests and interviews. The results of this study are PISA type mathematical problems to find out the students' mathematical communication skills of 10 items in the form of valid (practical construct response). These problems have a known effect from analyzing student answers and interviews when conducting test problems where students can explore their mathematical communication skills.
\end{abstract}

Keywords:

PISA type problems, mathematical communication. 


\section{PENDAHULUAN}

Matematika merupakan salah satu mata pelajaran yang terdapat dalam kurikulum pendidikan di Indonesia. Prestasi belajar matematika pelajar Indonesia internasional jauh tertinggal dari negara-negara lain. Berdasarkan rangking Program for International Student Assessment (PISA) (mathematics literacy) untuk tahun 2015 Indonesia menempati rangking 63 dari 69 negara (OECD, 2016).Fakta ini tentunya mencengangkan. Agar tidak terburu-buru menjustifikasi mtu pendidikan matematika di Indonesia, ada baiknya terlebih dahulu memperhatikan bagaimana sebenarnya soal yang digunakan dalam uji kompetensi PISA. Menurut Mardhiyanti (2011) penyelesaian soal-soal tipe PISA menuntut siswa untuk berpikir tingkat tinggi. Inilah salah satu poin yang menjadi perhatian, yang selanjutnya perlu kita pertanyakan apakah soal-soal yang digunakan dalam uji kompetensi matematika sekolah sudah menuntut siswa untuk berpikir tingkat tinggi? Sebagai acuannya, marilah perhatikan soal UN yang merupakan instrumen evaluasi nasional. Kemampuan berpikir tingkat tinggi belum terukur dan diketahui secara maksimal pada soal UN serta belum mampu mengeksplor kemampuan siswa secara maksimal dalam mengungkapkan gagasan matematika, merumuskan definisi matematika dan mengekspresikan generalisasi yang ditemukan melalui pengamatan,serta merefleksikan dan menjelaskan pemikiran mengenai gagasan matematik dan hubunganhubungannya. Hal serupa juga diungkapkan oleh Yunengsih dkk (2008) dalam hasil penelitiannya:

Soal-soal UN mata pelajaran matematika tingkat SMP/MTs tahun pelajaran 2005/2006 dan 2006/2007 tidak tersebar secara merata dalam hal aspek kognitif bahkan ada yang sama sekali tidak diukur oleh soal UN (conjecture/generalize/prve and solve non-routine problems). Soal-soal UN mata pelajaran matematika tingkat SMP/MTs hanya meminta siswa untuk melakukan penghitungan, sementara rumus/petunjuk yang diberikan dalam soal sudah cukup jelas arahannya. Kesimpulan dari penelitian tersebut menunjukkan bahwa soal-soal UN belum dapat mengukur seluruh aspek kognitif dan kemampuan berpikir tingkat tinggi siswa.

Beragam revisi telah dilakukan oleh pemerintah dalam kurikulum pendidikan untuk mencapai hasil terbaik dalam peningkatan kualitas pebelajaran matematika sekolah. Melalui K13 pemerintah mengarahkan proses evaluasi matematika sekolah pada kemampuan berpikir tingkat tinggi atau dalam istilahnya high order thinking (HOT).

Terkait dengan kemampuan berpikir tingkat tinggi ini, National Council of Teacher Matematics (NCTM, 2000) menetapkan bahwa terdapat 5 keterampilan proses yang harus dimiliki siswa melalui pembelajaran matematika yang tercakup dalam standar proses, yaitu : 1) pemecahan masalah (problem solving); 2) penalaran dan pembuktian (reasoning and proof); 3) komunikasi (comunication); 4) koneksi (conection); 5) representasi (representation). Keterampilan-keterampilan tersebut termasuk pada aspek berpikir matematika tingkat tinggi (high order mathematical thinking).

Setiap aspek berpikir tingkat tinggi mempunyai ruang lingkup yang sangat luas, agar tidak melebar maka yang fokuskan pada kemampuan komunikasi matematis. Kemampuan komunikasi matematis merupakan komponen penting dan fundamental 


\section{$\pi$ (Phi)}

bagi siswa dalam menyampaikan gagasan-gagasannya baik dalam menerapkan konsep matematika untuk kehidupan maupun menyelesaikan permasalahan matematika berdasarkan teori yang dipelajarinya.

Dilatarbelakangi

oleh permasalahan di atas, maka penulis mengembangkan soal- soal tipe PISA untukmengetahui kemampuan komunikasi matematis siswa tingkat SMP. Hal ini disebabkan PISA dirancang untuk mengetahui apakah siswa mampu menggunakan potensi matematika yang dimilikinya dalam kehidupan nyata. Siswa diberikan soal yang menuntut agar diterapkannya pengetahuan matematika dengan selalu mengaitkannya pada situasi atau permasalahan praktis yang ditemui dalam kehidupan sehari-hari (Hayat dan Yusuf, 2010). Lebih lanjut Mardhiyanti (2011) menjelaskan bahwa soal tipe PISA merupakan salah satu tipe soal yang dapat digunakan untuk melatih dan mengukur kemampuan komuniksi matematis.

Dari uraian di atas, peneliti tertarik untuk melakukan penelitian dengan judul "Pengembangan Soal Tipe PISA untuk Mengetahui Kemampuan Komunikasi MatematisSiswa Tingkat Sekolah Menengah Pertama di Kota Jambi”. Dengan tujuan untuk: 1) Menghasilkan soal tipe PISA yang valid dan praktis untuk mengetahui kemampuan komunikasi matematis siswa tingkat SMP. 2) Mengetahui efek potensial penerapan soal-soal tipe PISA yang dihasilkan terhadap kemampuan komunikasi matematis siswa SMPN 17 Kota Jambi.

\section{METODE PENELITIAN}

Subjek dan Lokasi Penelitian

Subjek penelitian ini adalah siswa tingkat SMP kelas IX SMP N 17 kota Jambi.

\section{Jenis Penelitian}

Penelitian ini merupakan penelitian pengembangan atau development research (Zulkardi, 2006). Bentuk diagram alir dari penelitian pengembangan adalah sebagai berikut:

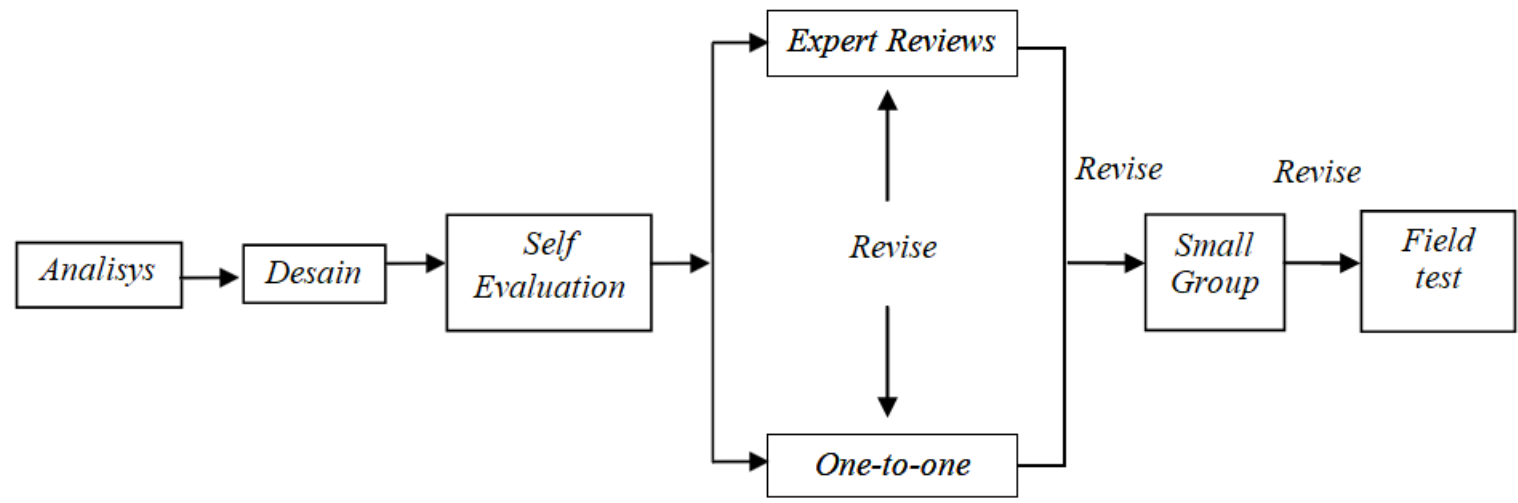

Gambar 1. Diagram Alir Pengembangan Soal Tipe PISA

\section{Prosedur Penelitian}

1. Tahap Analisis (Persiapan)

Pada tahap ini yang pertama kali dilakukan oleh peneliti adalah menganalisis materi sesuai dengan konten PISA. Selanjutnya menghubungi pihak sekolah untuk mempersiapkan penjadwalan dan penyusunan prosedur kerjasama.

2. Membuat Prototipe (Desain)

Pada tahap ini peneliti mendesain 


\section{$\pi$ (Phi)}

instrumen penilaian yang meliputi pembuatan kisi- kisi, penulisan indikator, mencari masalah yang sesuai konten dan berdasarkan kriteria soal-soal PISA.

3. Tahap Formative Evaluation (Evaluasi Formatif)

Pada tahap ini produk yang telah dibuatakan dievaluasi sendiri oleh peneliti. Selanjutnya uji coba produk diberikan kepada 3 kelompok uji coba yaitu expert review dan one to one, small group, field tes.

3.1 Self evaluation (Menilai sendiri)

Hasil dari self evaluation ini diperoleh prototipe I yang merupakan soal matematika tipe PISA untuk mengetahui kemampuan komunikasi matematis meliputi analisis dan desain.

3.2 Pakar (expert review) dan One-toone

\subsubsection{Pakar (expert review)}

Desain yang sudah dibuat oleh peneliti akan diuji validitasnya oleh pakar (expert review). Produk yang didesain akan dilihat, dinilai, dan dievaluasi isi, konstruk, dan bahasa dari prototipe.

\subsubsection{One-to-one}

Pada tahap ini, peneliti memanfaatkan tiga orang siswa untuk mengerjakan soal-soal prototype I. Komentar dari siswa digunakan untuk melakukan revisi terhadap desain soal-soal tipe PISA yang telah dibuat.

3.3 Small Group (Kelompok Kecil)

Prototipe II ini diujicobakan pada small group. Pada tahap small group ini siswa diminta untuk mengerjakan soal-soal yang merupakan prototipe II. Komentar dari siswa digunakan untuk melakukan revisi untuk field test.

\subsection{Field Test (Uji Lapangan)}

Pada tahap field test ini ujicoba perangkat soal dilakukan pada subjek penelitian. Perangkat soal yang diujicobakan haruslah memenuhi kriteria kualitas. Tiga kriteria kualitas tersebut adalah: validitas, kepraktisan dan efektivitas. Selain itu, soal-soal tersebut telah diuji validitas butir, reliabilitas, indeks kesukaran soal, dan daya beda.

\section{Teknik Pengumpulan Data}

Teknik pengumpulan data yang digunakan adalah: 1) Dokumentasi, 2) Walkthrough, 3) Tes, 4) Wawancara.

\section{Teknik Analisis Data}

1. Analisis Data Deskriptif

Analisis data deskriptif digunakan untuk menganalisis data setelah validasi dengan cara merevisi berdasarkan catatan validator, baik pada validasi pakar (walk trough) maupun pada one-to-one, dan small group. Hasil dari analisis inilah yang akan digunakan untuk merevisi soal-soal matematika tipe PISA yang dibuat oleh peneliti.

2. Analisis Data Hasil Tes Analisis data hasil tes dikategorikan berdasarkan tabel berikut:

Tabel 1: Kategori Tingkat Kemampuan Komunikasi Matematis Siswa

\begin{tabular}{cc}
\hline Nilai & Kriteria Kemampuan Komunikasi Matematis \\
\hline $64-84$ & Sangat baik \\
$43-63$ & Baik \\
$22-42$ & Cukup baik \\
$0-21$ & Kurang baik \\
\hline (Sumber: Modifikasi Arikunto, 2008) &
\end{tabular}




\section{Kriteria Keberhasilan}

Kriteria keberhasilan dalam penelitian ini adalah dihasilkannya produk soalsoal matematika tipe PISA tingkat SMP yang valid, praktis dan efektif untuk mengetahui kemampuan komunikasi matematis siswa.

\section{HASIL DAN PEMBAHASAN}

\section{Hasil yang Dicapai}

Tahapan-tahapan yang dibahas pada bab ini yaitu meliputi analisys, desain, prototyping (selfevaluation, expertreviews dan onetoone, serta smallgroup), dan fieldtest. Berikut ini adalah hasil dari setiap tahapan :

\section{Analisis}

Kegiatan analisis ini meliputi: 1) Analisis Siswa; mengamati siswa yang menjadi subjek penelitian yaitu siswa kelas IX SMP N 17 Kota Jambi berupa latar belakang pengetahuan siswa pengetahuan tentang materi tingkat SMP. 2) Analisis Kurikulum; mengidentifikasi K13 tingkat SMP mata pelajaran matematika yang digunakan sebagai rujukan untuk pengembangan soal tipe PISA. 3) Analisis Soal-soal PISA; mengamati soal-soal PISA dan framework PISA untuk memperoleh informasi tentang karakteristik soal PISA.

\section{Desain}

Kegiatan yang dilakukan peneliti dalam pendesainan soal matematika tipe PISA untuk mengetahui kemampuan komunikasi matematis ini adalah membuat perangkat instrumen sebagai berikut:

1) Kisi-kisi soal matematika tipe PISA untuk mengetahui kemampuan komunikasi matematis.

2) Kartu soal matematika tipe PISA untuk mengukur kemampuan komunikasi matematis.

3) Soal matematika soal tipe PISA untuk mengukur kemampuan komunikasi matematis yang berbentuk uraian.

4) Kunci jawaban soal tipe PISA untuk mengukur kemampuan komunikasi matematis.

\section{Prototyping}

1. Self Evaluation (Menilai sendiri) Adapun yang dilakukan adalah menganalisis materi dari kurikulum K13 sesuai dengan konten PISA (ruang dan bentuk, perubahan dan hubungan, bilangan, probabilitas dan ketidakpastian), selanjutnya dilakukan pendesaianan perangkat soal yang memenuhi karakteristik konten, konstruk, dan bahasa.

\section{Expert Reviews}

Tahap ini soal divalidasi dari segi konten, konstruk dan bahasa oleh pakar dan teman sejawat. Adapun saran dan komentar dari para pakar dan teman sejawat adalah sebagai berikut: 
Tabel 2: Komentar/Saran Validator

\begin{tabular}{|c|c|}
\hline Validator & Komentar/Saran \\
\hline $\begin{array}{l}\text { Dr. Buyung, } \\
\text { M.Pd }\end{array}$ & $\begin{array}{l}\text { 1. Kalimat soalnya masih banyak yang belum lugas. Jangan menggunakan } \\
\text { kalimat penjelasan yang terlalu panjang. } \\
\text { 2. Perbaiki redaksi kalimat dalam soalnya nomor 1, bahasanya terlalu } \\
\text { tinggi untuk siswa tingkat SMP. } \\
\text { 3. Sebaiknya buatlah pertanyaan yang konstruktif serta dapat membantu } \\
\text { siswa menyelesaikan masalah. } \\
\text { 4. Tunjukkan indikator kemampuan komunikasi mana yang diukur dalam } \\
\text { setiap setiap soal. } \\
\text { 5. Setiap soal harus jelas indikator kemampuan komunikasi yang diukur. }\end{array}$ \\
\hline $\begin{array}{l}\text { Ayu } \\
\text { Yarmayani, } \\
\text { M.Pd. }\end{array}$ & $\begin{array}{l}\text { 1. Sebaiknya buatlah soal yang menuntun siswa untuk berpikir mencari } \\
\text { solusinya, sehingga menjadi pertanyaan yang terstruktur dari satu } \\
\text { konteks. } \\
\text { 2. Tuliskan sumber informasi yang baku dalam konteks dan soal, sehingga } \\
\text { terdapat referensi yang bisa dipertanggungjawabkan. } \\
\text { 3. Lebih baik kalimat yang ringkas dan efektif agar tidak terlalu } \\
\text { membingungkan siswa dalam mengerjakan soal. }\end{array}$ \\
\hline $\begin{array}{l}\text { Relawati, } \\
\text { M.Pd. }\end{array}$ & $\begin{array}{l}\text { 1. Secara keseluruhan soal-soal PISA yang dibuat sudah bagus dan bisa } \\
\text { mengukur kemampuan komunikasi siswa dengan indikator-indikatornya, } \\
\text { tetapi harus diperhatikan apakah standar kompetensi dan kompetensi inti } \\
\text { pada kisi-kisi soal sudah mewakili semua standar kompetensi yang harus } \\
\text { dikuasai siswa pada level SMP. } \\
\text { 2. Perbaiki penulisan satuan rupiah. }\end{array}$ \\
\hline
\end{tabular}

Berdasarkan komentar/saran dari kegiatan expert reviews maka ilakukan revisi dengan keputusan revisinya adalah sebagai berikut:

Tabel 3: Keputusan Revisi dari Hasil Expert Reviews

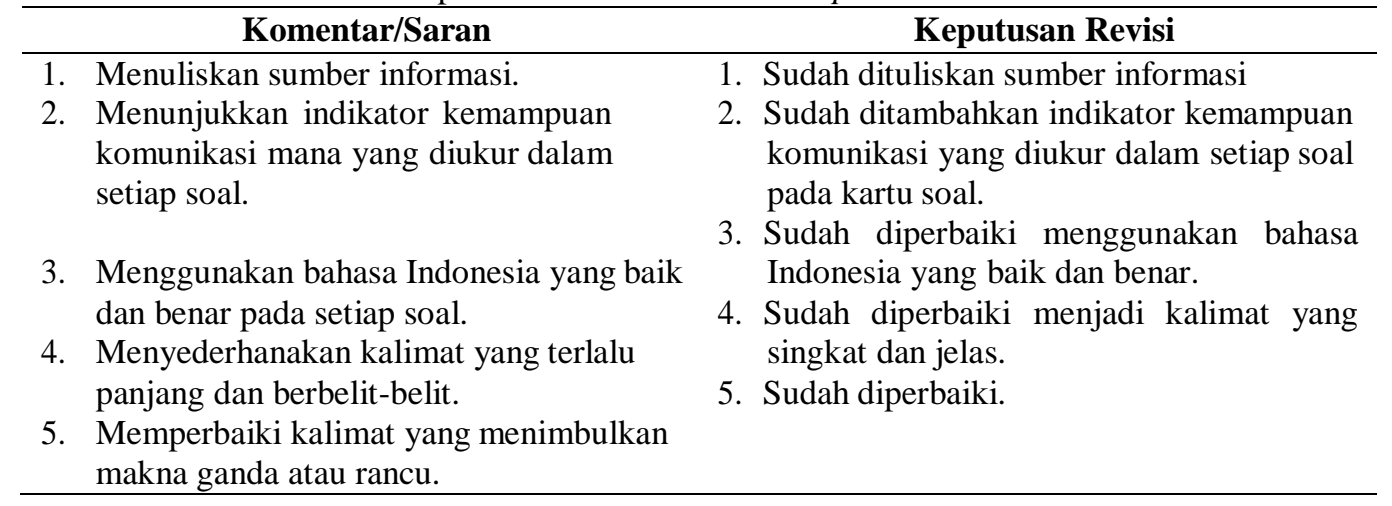

\section{One to one}

Pada tahap ini dilakukan ujicoba terhadap tiga orang siswa kelas IX SMP N 17 Kota Jambi yang memiliki tingkat kemampuan tinggi, sedang, dan rendah. Berdasarkan komentar dari kegiatan one to one maka dilakukan revisi dengan keputusan revisi sebagai berikut: 
Tabel 4: Keputusan Revisi dari Hasil One to one

\begin{tabular}{lll}
\hline \multicolumn{1}{c}{ Komentar/Saran } & \multicolumn{1}{c}{ Keputusan Revisi } \\
\hline 1. Kalimat pada soal nomor 1 susah dimengerti & 1. Sudah diperbaki. \\
2. Istilah-istilah yang digunakan kurang dpahami & 2. Sudah diperbaiki \\
3. Kalimat soalnya terlalu panjang & 3. Sudah diperbaiki. \\
\hline
\end{tabular}

Hasil dari tahap expert riviews dan one to one ini diperoleh prototipe II yang merupakan soal matematika tipe PISA untuk mengukur kemampuan komunikasi matematis berjumlah 10 butir.

\section{Small Group}

Small group terdiri dari 6 orang siswa

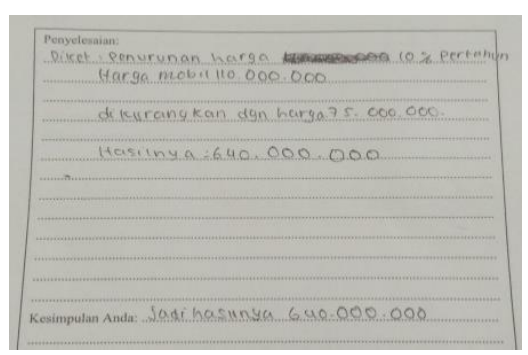

Gambar 1: Jawaban Siswa yang memiliki kemampuan berbeda yaitu; tinggi, sedang, dan rendah. Pelaksanaan small group ini dilakukan pada siswa di kelas IX G SMP N 17 Kota Jambi. Peneliti mengamati jawaban siswa, berikut ini salah satu gambar jawaban siswa:

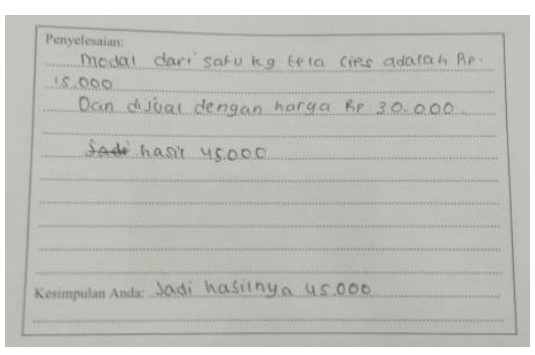

Gambar 2: Jawaban Siswa 


\section{$\pi$ (Phi)}

Jawaban siswa di atas dapat dilihat bahwa siswa tersebut tidak memahami soal dengan baik, sehingga tidak mampu memberikan jawaban yang benar. Dari hasil wawancara, diketahui siswa tersebut kesulitan memahami kalimat soal.

Berdasarkan komentar siswa pada aktvitas small group dan analisis terhadap jawabanjawaban siswa maka peneliti melakukan perbaikan (revisi) pada beberapa soal yang masih sulit untuk dijawab oleh siswa karena bingung memahaminya dengan merubah kalimat soal dalam soal menjadi lebih efektif. Hasil dari tahap small group ini diperoleh prototipe III dan selanjutnya dilakukan uji validitas, reliabilitas, indeks kesukaran, dan daya beda soal dengan hasil sebagai berikut: 1) validitas: seluruh soal valid; 2) reliabilitas: memiliki reliabilitas tinggi; 3) indeks kesukaran soal: kategori sedang utntuk seluruh soal, 4) daya beda: soal nomor 1 dan 5 memiliki daya beda sedang, selainnya memiliki daya beda tinggi.

5. Field Test

Field test dilaksanakan dikelas IXA SMP N 17 Kota Jambi dengan jumlah siswa 36 orang selama 3 jam pelajaran untuk mengetahui efek potensial soalsoal matematika tipe PISA yang telah dikembangkan, berikut hasilnya:

Tabel 5: Distribusi Nilai Akhir Kemampuan Komunikasi Matematis siswa

\begin{tabular}{ccc}
\hline Nilai & Jumlah & Kriteria Kemampuan Komunikasi Matematis \\
\hline $61-80$ & $0 \%$ & Sangat baik \\
$41-60$ & $17,24 \%$ & Baik \\
$21-40$ & $55,17 \%$ & Cukup baik \\
$0-20$ & $27,59 \%$ & Kurang baik \\
Total & $100 \%$ & \\
Rata-rata & 54,28 & Baik. \\
\hline
\end{tabular}

\section{Deskripsi dan Analisi Data Hasil Wawancara}

Berdasarkan hasil wawancara dengan siswa ketika pelaksanaan field test tergambar bahwa secara umum soal matematika tipe PISA yang dikembangkan dapat memicu siswa untuk mengeksplor kemampuan mekomunikasi matematisnya. Berikut ini beberapa kutipan hasil wawancara peneliti dengan siswa:

Peneliti $\quad$ : Apa keuntungan yang Anda dapatkan dengan soal matematika tipe PISA?

Siswa $1 \quad$ : Dapat membuat saya berpikir lebih kritis dan terurut sesuai dengan langkah penyelesaian soal. Selain itu juga soalnya membuat saya bisa menyampaikan pendapat dengan bahasa saya sendiri.

Siswa $2 \quad$ : Soal-soal seperti ini membuat saya berpikir tingkat tinggi dan membuat saya belajar menuliskan model matematika serta ide matematika dalam penyelesaiannya.

Siswa $3 \quad$ : Keuntungannya membuat saya lebih berpikir kritis dan kreatif mencari solusi masalah. Juga membuat saya harus bisa menyampaikan apa yang saya pikirkan tentang penyelesaiannya.

Siswa $4 \quad$ : Soal yang saya kerjakan tadi dapat membuat saya berpikir lebih kritis lagi dan belajar menuliskan pendapat saya.

Proses pengembangan soal ini telah menghasilkan soal-soal tipe PISA untuk mengukur kemampuan komunikasi matematis yang valid dan praktis. Selin itu juga hasil tesnya termasuk kategori baik dengan nilai rata-rata 54,28.
Berdasarkan hasil wawancara peneliti dengan siswa diketahui bahwa soal yang dikembangkan dapat memicu siswa untuk mengeksplor kemampuan komunikasi matematis dengan memberikan jawaban soal beserta 


\section{$\pi$ (Phi)}

penjelasan,

langkah-langkah penyelesaian, dan kesimpulan terhadah jawaban dari soal yang dikerjakan. Maka dapat dilihat bahwa perangkat soal tipe PISA yang dikembangkan memiliki efek potensial terhadap kemampuan komunikasi matematis siswa.

\section{SIMPULAN}

1. Telah dihasilkan perangkat soal matematika tipe PISA untuk mengetahui kemampuan komunikasi matematis siswa sebanyak 10 butir soal berbentuk uraian non objektif (open construct response) yang valid dan praktis.

2. Perangkat soal matematika tipe PISA yang dihasilkan mempunyai efek potensial terhadap kemampuan komunikasi matematis siswa SMP N 17 Kota Jambi. Hal ini dapat diketahui dari analisis jawaban siswa, hasil tes, dan wawancara dengan beberapa orang siswa ketika pelaksanaan uji coba soal dimana siswa dapat mengeksplor kemampuan komunikasi matematisnya.

\section{DAFTAR PUSTAKA}

Hayat B. \& Yusuf S. 2010. Bencmark: International Mutu Pendidikan. Jakarta: Bumi Aksara.

Mardhiyanti, Devi. 2011.
Pengembangan

Soal

Matematika Model PISA untuk Mengukur Kemampuan

Komunikasi Siswa SD. Jurnal Pendidikan Matematika departemen of Master Program on Mathematics education Faculty of Teacher Training and Education Sriwijaya University, Volume 5, No 1. Retrievied 5 Ferbruari 2016, from ejournal.unsri.ac.id

NCTM. 2000. Principles and Standard for School Mathematics. Reston, VA: NCTM.

OECD. 2009. The PISA 2009 Assesment Framework:

Mathematics, reading science and problem solving knowledge and skills. Retrievied 5 November 2015, from https://www.pisa.oecd.org/datao ecd/38/51/33707192.pdf.

Yunengsih, dkk. 2008. Ujian Nasional: Dapatkah Menjadi Tolak Ukur Standar Nasional Pendidikan? Jakarta: Departemen Riset Putera Sampoerna Foudation.

Zulkardi. 2006. Formative Evaluation: What, Why, When, and How. Retrivied 20 November 2016, from www.reocities.com/zulkardi/bo oks.html. 